\title{
A formação de professores para/na educação inclusiva: capacitação em colaboratividade no contexto do ensino remoto
}

Diolinda Franciele Winterhalter ${ }^{1}$ Andrea Borges Monzón ${ }^{2}$

\begin{abstract}
Resumo:
Verificou-se em nossa instituição a demanda de atender alunos com necessidades educacionais específicas (NEEs), tanto no âmbito pedagógico, quanto relativo à acessibilidade e inclusão, especialmente durante o ensino remoto. Observou-se também a demanda pela capacitação teórico-prática de licenciandos, no sentido de produzir um olhar mais atento e inclusivo do/no fazer docente. Nesse contexto, configurou-se o projeto Capacitação, Acessibilidade e Inclusão. Nossos objetivos dividem-se nos eixos: 1) propiciar atendimento pedagógico a alunos com NEEs, de forma colaborativa; 2) ampliar a formação de professores pré-serviço para práticas educativas inclusivas. Para tanto, a equipe foi composta por duas educadoras em serviço do IFRS e três bolsistas, graduandas das licenciaturas da instituição. Essas bolsistas atuaram como monitoras, atendendo virtualmente os alunos com NEEs durante o ensino remoto, mediando demandas pedagógicas individuais dos alunos com NEEs junto às diversas disciplinas e aos professores. Foram realizadas leituras dirigidas e dialógicas e encontros semanais da equipe do projeto, além de levantamentos de particularidades e planejamentos pedagógicos individualizados. Conclui-se que a formação de professores para a educação inclusiva, sob a perspectiva da colaboratividade, aqui contribuiu tanto para o desenvolvimento e a aprendizagem dos alunos com NEEs atendidos durante o ensino remoto quanto para formação inicial e contínua das educadoras e bolsistas envolvidas.
\end{abstract}

\section{Palavras-chave:}

Formação docente. Práticas educativas inclusivas. Colaboratividade.

\footnotetext{
1 Mestre em Educação (UFSM). Instituto Federal do Rio Grande do Sul - Campus Feliz. E-mail: franciele.winterhalter@feliz.ifrs. edu.br. Orcid: https://orcid.org/0000-0003-4917-0855.

2 Doutora em Letras (UFRGS). Instituto Federal do Rio Grande do Sul - Campus Feliz. E-mail: andrea.monzon@feliz.ifrs.edu.br. Orcid: https://orcid.org/0000-0003-2265-2985.
} 


\title{
Teachers' education for/in inclusive education: collaborative training in the context of remote learning
}

\begin{abstract}
:
We observed in our institution the need of supporting students with special educational needs (SENs) in terms of pedagogical aspects as well as accessibility and inclusion, especially during the remote learning. We also observed the need for theoretical-practical training for undergraduate students, in order to provide a more aware and inclusive perception of teachers' professional knowledge. In this context, the project Training, Accessibility, and Inclusion was designed. The aims were: 1) provide pedagogical support for students with SENs in a collaborative way; b) increase undergraduates' education for inclusive educational practices. Our team was composed of two educators from IFRS and three undergraduate fellows from courses of Language/Literature and Chemistry in our institution. These undergraduate fellows worked as monitors virtually supporting the students with SENs during the remote learning, mediating their individual pedagogical necessities regarding the various subjects and teachers/professors. We performed formative and dialogical readings and also weekly meetings of the team, besides particularities surveys and individual pedagogical planning. We found that teachers' education for inclusive education in a collaborative perspective contributed both for the development and learning of students with SENs supported during the remote learning and for the initial and continuous development of the educators and fellows involved.
\end{abstract}

\section{Keywords:}

Teachers' education. Inclusive educational practices. Collaborativity.

\section{Formación de docentes para la inclusión educativa: capacitación colaborativa en el contexto de enseñanza remota}

\section{Resumen:}

Se verificó en nuestra institución el menester de atender alumnos con necesidades educativas especiales (NEEs) tanto en ámbito pedagógico como relativo a la accesibilidad e inclusión. Se observó también demanda por capacitación teórico-práctica de académicos de licenciaturas, en el sentido de producirse una perspectiva más atenta e inclusiva del hacer docente. En este contexto, se configuró el proyecto Capacitación, Accesibilidad e Inclusión. Nuestros objetivos son: 1) propiciar atendimiento pedagógico a alumnos con NEEs de una forma colaborativa; 2) ampliar la formación de futuros profesores para prácticas educativas inclusivas. Para eso el equipo fue compuesto de dos educadoras de IFRS y tres becarias, estudiantes de las licenciaturas de la institución. Esas becarias actuaron como monitoras, atendiendo en línea a los alumnos con NEEs durante la enseñanza remota, mediando demandas pedagógicas individuales junto a diversas disciplinas y profesores. Se hicieron lecturas dirigidas y dialógicas y encuentros semanales del equipo del proyecto, además de sondeos acerca de particularidades y planeamientos pedagógicos individualizados. Se concluye que la formación de profesores para la inclusión educativa, en perspectiva colaborativa, aquí contribuyó tanto para el desarrollo y aprendizaje de los alumnos con NEEs como para la formación inicial y continua de las educadoras y becarias involucradas.

\section{Palabras clave:}

Formación de docentes. Prácticas educativas inclusivas. Colaborativo. 


\section{Introdução}

Após várias movimentações históricas, políticas e sociais, a Lei 11.892, de 29 de dezembro de 2008, instituiu a Rede Federal de Educação Profissional, Científica e Tecnológica. Nesse contexto, os Institutos Federais de Educação Ciência e Tecnologia (IFs) nascem como política pública que visa a atender as demandas sociais de acesso à educação e ao conhecimento por meio de uma formação profissional pública e de qualidade.

Dentre suas finalidades e características, está a oferta de educação profissional e tecnológica em todos os seus níveis e modalidades, proporcionando formação e qualificação aos cidadãos com vistas à atuação profissional em diversos setores. Da mesma forma, visa a construir a formação como processo educativo e investigativo de criação com propostas de soluções às demandas sociais.

Quando se fala em oferta da educação em todos os seus níveis e modalidades, além de estarmos trazendo o recorte de um dos diferenciais da educação produzida nos Institutos Federais (IFs), evidencia-se também a educação das pessoas com alguma necessidade educacional específica (NEEs), o que entendemos por educação inclusiva. A educação especial apresenta-se na Lei de Diretrizes e Bases da Educação Nacional (LDB) como uma das modalidades da educação e é destinada às pessoas com algum transtorno de aprendizagem, deficiência, transtornos globais do desenvolvimento e altas habilidades ou superdotação (BRASIL, 2013; IFRS, 2014; SONZA, 2020).

Diante disso, os IFs precisaram criar estratégias para propor uma formação capaz de atender também às especificidades dos educandos que apresentam algum transtorno, deficiência e/ou habilidade. Eis que surgem os NAPNEs (Núcleos de Atendimento/Apoio às Pessoas com Necessidades Específicas) uma proposição da Secretaria de Educação Profissional e Tecnológica do Ministério da Educação (SETEC/MEC), através do Programa TECNEP (Tecnologia, Educação e Profissionalização para Pessoas com Necessidades Educacionais Específicas). Segundo Sonza (2020), o objetivo era ampliar as estratégias para firmar uma política de educação inclusiva nos IFs, divulgando conceitos, experiências e sensibilizando as comunidades escolares da educação básica e profissional para as demandas das necessidades educacionais específicas.

[...] os NAPNEs têm para a Rede Federal de Educação Profissional e Tecnológica, a mesma importância que as Salas de Recurso Multifuncionais exerce nas redes municipais e estaduais de ensino ou o Projeto INCLUIR, nas Universidades Federais. Isso demonstra a relevância da criação e da atuação dos núcleos nessas instituições, que atuam como espaços de reflexão, luta e concretização de ações em prol da inclusão plena, permanência e êxito dos estudantes com necessidades educacionais específicas. (SONZA, 2020, p. 3).

No Instituto Federal de Educação, Ciência e Tecnologia do Rio Grande do Sul (IFRS), a Resolução n. ${ }^{\circ}$ 20, de 2014, aprova o regulamento dos NAPNEs para seus dezessete campi como setor propositivo e consultivo que media a educação inclusiva. Dentre suas finalidades, tem-se:

I - incentivar, mediar e facilitar os processos de inclusão educacional e profissionalizante de pessoas com necessidades educacionais específicas na instituição; [...] IV - participar do Ensino, Pesquisa e Extensão nas questões relacionadas à inclusão de pessoas com necessidades específicas nos âmbitos estudantil e social; [...] IX - buscar a quebra de barreiras arquitetônicas, educacionais, comunicacionais e atitudinais na Instituição; [...] X - promover capacitações relacionadas à inclusão de pessoas com necessidades educacionais específicas. (Art. 2 da Resolução no. 20, de 2014, do IFRS).

Tendo em vista tais aspectos, bem como a realidade crescente dos casos de estudantes com necessidades educacionais específicas (NEEs) ${ }^{3}$, no Campus Feliz do IFRS, percebeu-se que

3 Salienta-se que, no IFRS - Campus Feliz, bem como no âmbito deste trabalho, a concepção de NEEs se constitui de modo que sejam acolhidas as demandas de estudantes com deficiência(s), transtorno(s) e/ou dificuldade(s) de aprendizagem, além de altas habilidades, percebidas por meio de laudos e/ou com base em observações dos educadores. 
era necessário dispor de mais recursos humanos, bem como de uma metodologia de trabalho formativa e colaborativa, para que o NAPNE tivesse condições não apenas de colaborar com os processos educativos das pessoas com NEEs, participar das atividades de ensino e buscar a quebra das barreiras na instituição de forma ampla, mas, também, promover a capacitação acerca da educação inclusiva, evidenciando os desafios que isso representa nas práticas docentes.

Diante disso, o NAPNE, em parceria com uma docente, integrante do Núcleo à época, propôs o projeto de ensino Capacitação, Acessibilidade e Inclusão em Colaboratividade, com o objetivo de promover a capacitação e inclusão dos diferentes sujeitos no âmbito escolar e acadêmico, no que se refere aos distintos cursos ofertados na instituição. Dentre as intenções específicas estavam: possibilitar capacitação referente à acessibilidade e inclusão para a comunidade escolar; oferecer monitoria para estudantes com deficiência, cujo acompanhamento das aulas requeria auxílio de um(a) monitor(a) para realização das atividades no âmbito escolar/acadêmico; ampliar a formação dos estudantes dos cursos de licenciatura do Campus Feliz, no que se refere às práticas inclusivas; e, por fim, disseminar os saberes desenvolvidos no âmbito da monitoria.

A seguir, traremos aspectos sobre as experiências formativas vivenciadas de modo colaborativo e dialógico entre professoras pré-serviço, ou seja, em processo de formação inicial, e, servidoras em serviço, portanto, em formação contínua.

\section{Formação de professores e educação inclusiva: os desafios das práticas educativas}

De acordo com a Resolução do CNE 02, de vinte de dezembro de 2019, todo curso de licenciatura deve ter uma BNC-Formação, que estabelece que o Grupo I de disciplinas, totalizando oitocentas horas-relógio, deverá ser composto por "conhecimentos científicos, educacionais e pedagógicos e fundamentam a educação e suas articulações com os sistemas, as escolas e as práticas educacionais" (Artigo 11, CNE, 02/2019, s.p). Desse modo, o Projeto Pedagógico de Curso (PPC) de todas licenciaturas prevê componentes que tratem de Didática, Educação Especial/Inclusiva, Diversidade, Psicologia da Educação, Políticas Educacionais, Avaliação, Currículo e o trabalho docente, sob o viés das deficiências, dos transtornos e/ou das dificuldades de aprendizagem (PIMENTEL, 2012). Ocorre, entretanto, que mesmo com todos esses conteúdos contemplados na matriz curricular e com a realização dos estágios supervisionados obrigatórios, os licenciandos não cheguem a vivenciar plenamente a educação inclusiva na prática e, com isso, consigam construir os saberes necessários para uma docência inclusiva.

O conhecimento da legislação frente à educação inclusiva, bem como as atualizações e/ ou modificações dessas leis também têm sua extrema importância na capacitação contínua de docentes e demais profissionais educadores, contudo ela ainda não é suficiente. Segundo Souza e Rodrigues (2015):

O conhecimento de leis que amparam a inclusão não basta para dizer que uma escola ou professor são inclusivos. [...] Ser um professor inclusivo vai muito além de cursos e certificados. Necessita uma mudança na forma de ver o aluno diferente, nas práticas pedagógicas que excluem e no engajamento em formações continuadas. Para ser inclusão tem que haver aprendizagem e para potencializar a aprendizagem é importante o envolvimento do docente. (SOUZA; RODRIGUES, 2015, p. 22986).

É importante que essa aprendizagem associada ao desenvolvimento de um olhar mais inclusivo do docente componham uma formação processual e nunca acabada. Pimentel (2012, p. 139) coloca que "[...] os professores da escola básica se consideram despreparados para o trabalho com estudantes com deficiência, mantendo, desta forma, uma organização curricular rígida e práticas 
avaliativas homogêneas". Na verdade, como cada aluno com NEE(s), seja(m) ela(s) deficiência(s) e/ou algum transtorno ou dificuldade de aprendizagem, demandará estratégias pedagógicas e adaptações curriculares individualizadas, nunca se está completamente preparado para a educação inclusiva. Por isso, o que defendemos aqui é que o trabalho docente inclusivo seja colaborativo, reflexivo e dialógico de forma contínua. Como salienta Pimentel (2012, p. 140), ainda, a "[...] inclusão educacional requer professores preparados para atuar na diversidade, compreendendo as diferenças e valorizando as potencialidades de cada estudante de modo que o ensino favoreça a aprendizagem de todos". A autora afirma também que, em não havendo essa formação docente contínua e reflexiva frente à inclusão, é gerado o fenômeno que ela denomina de "pseudoinclusão", no qual o aluno com NEEs figure na escola, mas não "[...] esteja devidamente incluído no processo de aprender" (PIMENTEL, 2012, p. 140).

Essas são questões que evidenciam a necessidade de formação/capacitação para a docência com estudantes que possuem alguma NEE. Conforme evidenciamos, o processo inicial de formação de professores aborda pressupostos legais, teóricos e práticos acerca do assunto. No entanto, tendo em vista as especificidades que a docência inclusiva requer, bem como a pluralidade de transtornos, deficiências e habilidades que podem ser vivenciadas nos contextos escolares e acadêmicos, enfatizamos a importância da formação dos educadores ser contínua, de modo que esses tenham condições de ampliar e atualizar seus conhecimentos acerca da educação inclusiva e, assim, consigam, de fato, atender às NEEs de seus educandos, contribuindo para que eles construam aprendizagens significativas e uma formação de qualidade.

No que se refere à formação docente, Freire (1996, p. 50) elenca alguns saberes necessários à prática educativa. Um deles é o de que "Ensinar exige consciência do inacabamento"; aqui, entendemos "inacabamento", justamente, como a necessidade de continuidade da formação para/na prática docente, a qual destacamos que precisa ser ampliada para além da formação inicial, por meio de capacitações e experiências formativas durante a atuação prática.

No entanto, para que a formação continuada seja possível, destacamos outros saberes que se fazem necessários. Freire (1996, p. 35) traz também que "Ensinar exige risco, aceitação do novo e rejeição a qualquer forma de discriminação [...]" e, quando se fala em educação inclusiva, os desafios são vários, uma vez que são enfrentados riscos ao lidar com situações novas, que requerem adaptações de conteúdos, de avaliações, de métodos de ensino. Esses riscos exigem aos educadores repensarem suas práticas pedagógicas, muitas vezes, já consolidadas nas rotinas dos mesmos. Além disso, na maioria dos casos, arriscar-se requer, ainda, lidar com fragilidades físicas, cognitivas e/ ou emocionais de modo a impedir qualquer forma de preconceito ou discriminação, bem como fortalecer as condições para um ambiente de aprendizagem inclusivo e acolhedor.

Entendemos que a educação inclusiva não corrobora com uma organização curricular rígida nem com práticas avaliativas homogêneas. Muito pelo contrário, ela exige estratégias pedagógicas específicas, bem como adaptações curriculares individualizadas de acordo com as especificidades dos estudantes e as realidades de seus cursos de formação (PIMENTEL, 2012). Isso nos leva a outro saber elencado por Freire (1996, p. 113): “Ensinar exige reflexão crítica sobre a prática”. A reflexão crítica sobre a prática é o que torna possível avaliar e perceber, neste contexto, se as práticas educativas estão sendo inclusivas, bem como, caso necessário, partir em busca de novas possibilidades didáticas e metodológicas.

Com isso, percebemos que a reflexão crítica, assim como o movimento de busca por novas aprendizagens, ou seja, o processo de formação contínua, por isso, também compreendida como formação processual, exige, conforme destaca Freire (1996), “[...] saber escutar [...]” os educandos que sinalizam suas fragilidades, potencialidades e interesses de diferentes formas. Assim, partindo das especificidades dos estudantes, precisamos ler, estudar, pesquisar e dialogar para encontrar as estratégias didático-pedagógicas mais adequadas. Desse modo, concordamos com Freire (1996, p. 29) acerca de outros saberes necessários às práticas educativas: "Ensinar exige pesquisa [...]" e, 
"[...] disponibilidade para o diálogo [...]" para que este processo de formação contínua não seja solitário, mas, ao contrário, possa ser colaborativo e, sobretudo, proporcione verdadeiramente a inclusão, não a "pseudoinclusão" (PIMENTEL, 2012; FREIRE, 1996).

Sendo, portanto, colaborativa e dialógica, a formação dos membros da equipe do projeto não foi solitária, pois, de acordo com Booth e Ainscow (2011 apud TOLEDO et al., 2020, p. 3), os “[...] processos de formação de professores, portanto, não devem ser solitários. Ao contrário, por meio de trocas de experiências e saberes, é possível (re)pensar culturas, políticas e práticas no contexto escolar". Assim, de modo colaborativo, pode-se construir uma formação mais próxima às particularidades da educação inclusiva, por meio do diálogo estabelecido entre licenciandas, educadores, educandos e suas famílias.

\section{Capacitação de licenciandas através de um projeto de ensino: a inclusão na prática}

O projeto de ensino CAIC - Capacitação, Acessibilidade e Inclusão do IFRS foi proposto para promover a capacitação e inclusão dos diferentes sujeitos no âmbito escolar e acadêmico, tendo, portanto, como um de seus eixos, a capacitação. Nesse sentido, a capacitação pode ser compreendida de modo amplo, pois está relacionada à formação de professoras pré-serviço, ou seja, acadêmicas dos cursos de licenciatura em Letras - Português e Inglês e, em Química, as quais, portanto, estavam em processo de formação inicial, bem como de servidoras em serviço, uma docente da área de Letras e uma pedagoga (Técnica Administrativa em Educação - TAE), que vivenciaram um processo de formação contínua de modo dialógico e colaborativo em serviço (TOLEDO; FAÇANHA; ARRUDA, 2020).

Cabe acrescentar que o projeto foi criado com foco em duas linhas de ação: 1) proporcionar atendimento pedagógico, por meio de monitoria, aos estudantes com alguma deficiência e/ou transtorno de aprendizagem; 2) ampliar a formação dos acadêmicos dos cursos de licenciatura do campus, no que se referia às práticas inclusivas. Essas intenções foram basilares para a estruturação das ações e, estavam diretamente relacionadas, pois tanto os estudantes com NEEs precisavam receber apoio pedagógico de um monitor com capacitação para ensinar quanto as licenciandas poderiam se beneficiar ampliando as oportunidades formativas acerca da docência e práticas pedagógicas inclusivas, muitas vezes, restritas ao estágio curricular.

Embora o curso de licenciatura ofereça suporte teórico, por meio dos referenciais estudados nos componentes curriculares que abordam questões relativas à educação inclusiva, entendemos que, a partir das demandas vivenciadas nos atendimentos com os estudantes que possuíam alguma NEEs e, das discussões tecidas nos encontros do NAPNE, era necessário incluir momentos de estudos sobre os temas específicos com os quais estávamos trabalhando. Com isso, passamos a refletir de modo teórico e prático, em momentos de leituras dirigidas, sobre autores referência em temas como Transtorno do Déficit de Atenção e Hiperatividade - TDAH -, Dislexia, Disgrafia, Disortografia, Dislalia, Discalculia, Paralisia Cerebral, adaptações curriculares, letramento para surdos e Plano Educacional Individualizado (PEI). Nesses momentos, tanto as servidoras quanto as licenciandas, que eram bolsistas do projeto de ensino e atuavam como monitoras dos estudantes com NEEs, alternavam o protagonismo ao propor as problematizações acerca de cada um dos temas.

Tais momentos formativos foram fundamentais para que, de modo colaborativo, pudéssemos entender melhor os casos em atendimento e, com isso, encontrássemos as estratégias didático-pedagógicas mais adequadas para os atendimentos nas monitorias de acordo com as particularidades dos estudantes e as demandas que eles apresentavam. Da mesma forma, foi possível realizar orientações mais direcionadas junto aos docentes no sentido de flexibilizar e adaptar conteúdos, prazos, atividades e avaliações, o que, certamente, viabilizou aprendizagens significativas para as monitoras e também para os alunos(as) atendidos por elas. 


\section{A perspectiva da colaboratividade: uma metodologia de trabalho formativa}

Antes mesmo do início do ensino remoto no IFRS, que foi denominado de APNPs (Atividades Pedagógicas Não Presenciais) e das atividades das bolsistas, foi realizado um levantamento de necessidades e demandas pedagógicas individualizadas (Figura 1). Para tal, houve reuniões virtuais do NAPNE, Assistência Estudantil e Setor de Ensino com os estudantes e/ou seus familiares, no caso dos menores de idade, de modo a sondar os desafios e potencialidades que poderíamos vivenciar no ensino remoto, o que possibilitou compreender melhor quais conteúdos, estratégias, materiais e adaptações poderiam ser benéficas e significativas. Todavia, as famílias não foram a única fonte para o levantamento, pois também se levou em consideração informações que constavam de laudos (se houvesse), pareceres pedagógicos vindos de escolas anteriores, PEIs e possíveis especificidades frentes às TICS e ao ensino remoto.

Figura 1: Levantamento de necessidades dos alunos com NEEs

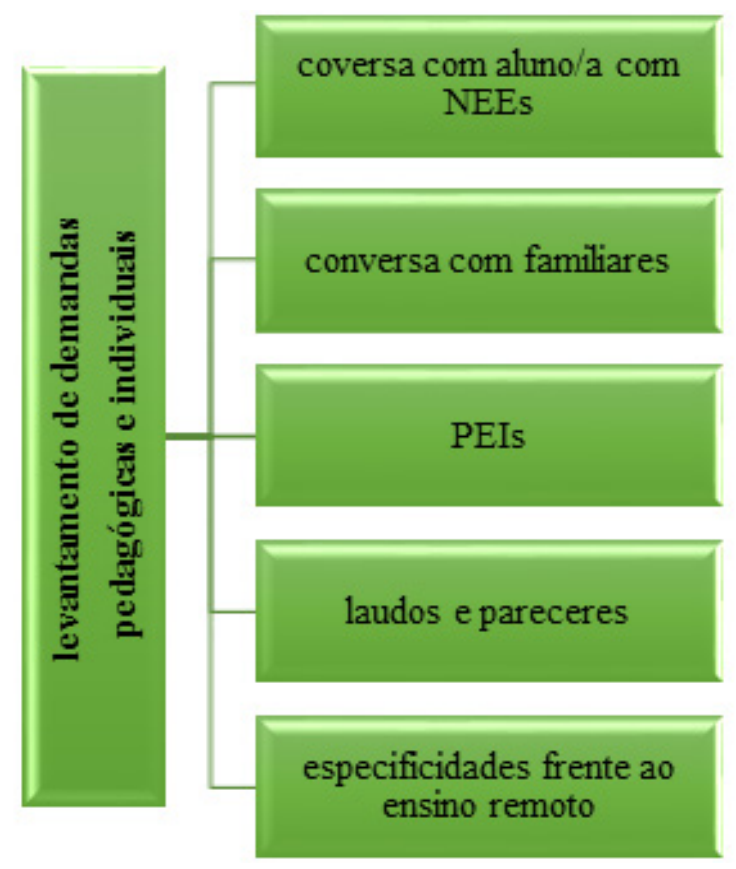

Fonte: Elaborado pelas autoras.

Salientamos que a colaboratividade foi algo evidente também nos levantamentos das necessidades pedagógicas, levando-se em conta a participação dos vários atores das comunidades interna e externa ao IFRS. Conhecer e ouvir as demandas através dos próprios alunos, familiares e profissionais que já tiveram ou ainda têm contato com o aluno com NEEs, enriquece o panorama multifacetado inicial.

Foram atendidos e acompanhados alunos com transtornos/dificuldades tais como: TDAH (dois casos), dislexia (um caso inconclusivo), dislalia (um diagnóstico em aberto) e discalculia (hipótese diagnóstica externa) e Transtorno do Espectro Autista-Síndrome de Asperger (com laudo). Já no que diz respeito aos alunos com alguma deficiência, foram acompanhados os seguintes casos: uma aluna com paralisia cerebral (e TDAH), uma aluna surda que utiliza Libras, uma aluna surda que não utiliza Libras, um aluno cadeirante com paralisia cerebral, um aluno com baixa visão, um aluno com perda auditiva. Salienta, então, que foram atendidos e/ou acompanhados dez alunos com NEEs.

Para cada um desses dez alunos, havia uma planilha compartilhada, de modo que fossem registrados os encaminhamentos dados por todos os membros do projeto junto a esse discente 
durante o ensino remoto. Em tal documento, eram registrados: 1) data e razões de contatos por telefone, e-mail ou Whatsapp; 2) reuniões com o próprio aluno ou também com seus familiares; 3 ) atendimentos, dificuldades encontradas, estratégias utilizadas, trocas com professores do aluno; 4) ausência, por parte do aluno com NEEs, ao comparecer (virtualmente) a atendimentos agendados, bem como em responder mensagens e tentativas de contato. Esses registros, para além da documentação das ações deste projeto, proporcionaram a construção e a aplicação colaborativa e dialógica de conhecimento e de experiências pedagógicas inclusivas.

Segundo Tardif (2002), a reflexão sobre o saber-fazer docente é um dos conhecimentos mais caracteristicamente constitutivos da formação do professor. Desse modo, as reflexões e atividades formativas propiciadas pelo projeto às bolsistas e às servidoras foram produzindo nelas conhecimentos formativos e foram construindo significados sobre a docência inclusiva na prática, através das interações com familiares, alunos(as) com NEEs, professores desses alunos. De acordo com as demandas pedagógicas e/ou tecnológicas de cada aluno(a) com NEE, era preciso se preparar para planejar, ou seja, era preciso estudar e levantar dados antes de preparar atividades e/ou propostas para os atendimentos aos alunos(as). Para além de conhecer o diagnóstico/laudo ou hipótese diagnóstica sobre cada aluno a ser atendido, foi importante para todos do projeto estabelecer estratégias pedagógicas inclusivas, bem como materiais didáticos acessíveis, para cada indivíduo. Assim, foi de extrema valia pensar cada estudante de inclusão para além da sua deficiência e/ou transtorno/dificuldade, pois construiu-se colaborativamente um repertório de possibilidades de adaptação e acessibilidade para cada disciplina em cada contexto. Salienta-se, contudo, que esse repertório não precisa ser estanque nem definitivo. A cada momento, especialmente durante o ensino remoto, era imprescindível rever as estratégias e materiais didático-pedagógicos, a fim de lidar com as demandas tanto acadêmicas quanto socioemocionais dos alunos com NEEs.

Esses também foram acompanhados através da gestão dos PEIs (Planos Educacionais Individualizados) dos mesmos. Através do e-mail do NAPNE e do Google Drive, foram encaminhados os modelos de PEIs para cada docente de cada disciplina cursada por nove dos alunos com NEEs. Como os PEIs têm o histórico das experiências escolares dos alunos com NEEs e indicações gerais de estratégias e demandas pedagógicas para cada aluno, individualmente, ele se configurou como uma ferramenta rica em informações sobre como planejar atendimentos e elaborar atividades por parte tanto das bolsistas-monitoras quanto dos professores. Além disso, os docentes enviavam suas dúvidas e demandas para o NAPNE, sendo que essas informações nutriam os planejamentos da equipe quanto às disciplinas nas quais os alunos atendidos necessitavam maior apoio, se eles estavam conseguindo acompanhar atividades (adaptadas ou não pelos docentes), se haviam realizado avaliações, se tinham dúvidas etc. As informações fornecidas pelas bolsistas-monitoras também nutriam os planejamentos, uma vez que elas tinham contato virtual mais frequente com os alunos com NEEs, os quais participavam ativamente dos atendimentos e majoritariamente respondiam aos contatos realizados.

No contexto do ensino remoto, os recursos didático-pedagógicos foram disponibilizados pelos professores das disciplinas na plataforma Moodle e a interação se dava através de momentos síncronos e assíncronos. A comunicação podia ser realizada através do próprio Moodle ou WhatsApp e e-mail. Reitera-se que os desafios impostos pela adaptação ao meio digital com fins educacionais foi algo vivenciado não somente por alunos com NEEs, mas por todas as partes: alunos, professores, setor de ensino, NAPNE e familiares. 


\section{Aprendizagens formativas e colaborativas construídas no contexto de um ensino remoto inclusivo}

De modo geral, conseguimos promover a capacitação e inclusão desses diferentes sujeitos no âmbito escolar e acadêmico. Ao longo da realização do projeto, foi oferecida a monitoria para estudantes com NEEs. $\mathrm{O}$ auxílio com as atividades escolares prestado por licenciandas funcionou como uma via de mão dupla, pois, tanto os estudantes assistidos foram beneficiados com o apoio pedagógico recebido quanto as licenciandas também tiveram a oportunidade de desenvolver a docência, frente aos desafios das práticas pedagógicas inclusivas.

Os relatos das monitoras acerca dos atendimentos evidenciaram o quanto essa experiência as movimentou no sentido de realizar pesquisas e estudos em busca das melhores estratégias didáticas para atender às especificidades dos estudantes com NEEs, o que se entende como experiência essencialmente formativa e que, portanto, contempla a intenção de ampliar a formação dos estudantes dos cursos de licenciatura, no que se refere às práticas inclusivas (AMARAL et al., 2021; POSTAY et al., 2020). Entende-se que esse momento formativo foi vivenciado em todas as ações desenvolvidas colaborativamente no projeto, pois as bolsistas, como monitoras dos estudantes com NEEs, participaram ativamente das reuniões semanais com a equipe do projeto, nas quais discutiam-se sobre os casos em atendimento e as demandas que os estudantes com NEEs traziam. Além disso, os momentos de leituras dirigidas e discussões também ofereceram suporte teórico para o desenvolvimento das práticas pedagógicas desenvolvidas nas monitorias, bem como oportunizaram que as bolsistas preparassem os materiais e propusessem as discussões. $\mathrm{Na}$ verdade, devido ao caráter colaborativo do projeto, as leituras e os debates se configuraram como momentos reflexivos formativos para as licenciandas, como professoras pré-serviço, e, para essas pesquisadoras, como educadoras em serviço. As vivências e reflexões eram construídas e trocadas de forma horizontal e não hierarquizada, uma vez que buscávamos uma capacitação colaborativa.

Devido à pandemia e ao ensino remoto, as monitoras precisaram criar diferentes mecanismos para os atendimentos com os(as) alunos(as) com NEEs por meio de videochamadas, grupos de WhatsApp, dentre outros, visando à melhor forma de comunicação com os(as) alunos(as) com NEEs. Tais ações demandaram planejamento e também, uma forma de organização para os atendimentos. Ainda no sentido da comunicação, atuaram como mediadoras junto aos professores no processo de flexibilização de prazos e solicitação de adaptação de atividades.

Do mesmo modo, o registro periódico das ações e encaminhamentos realizados junto aos estudantes com NEEs e/ou suas famílias possibilitou, além da criação do histórico dos atendimentos, também a aprendizagem de observar, refletir e registrar as particularidades dos estudantes, elementos considerados essenciais na prática docente. Da mesma forma, as licenciandas participaram de algumas reuniões com o colegiado de professores e também com as famílias dos estudantes, momentos em que, de modo dialógico, puderam aprender sobre a postura profissional e o posicionamento docente no ambiente escolar.

Tendo vivenciado essas experiências formativas e, por meio disso, colaborado com o processo de fortalecimento da acessibilidade e inclusão na instituição, bem como para a permanência e o êxito dos estudantes com NEEs, as bolsistas disseminaram os saberes desenvolvidos no âmbito da monitoria também em participações em eventos acadêmicos, publicações e apresentações para as quais foram convidadas.

Houve, portanto, a instrumentalização da equipe ao longo do projeto através do aporte teórico e prático para o atendimento e apoio a alunos não somente com deficiências, mas também com transtornos/dificuldades de aprendizagem. Isso possibilitou não apenas a ampliação da formação inicial e continuada das educadoras, mas também o aumento da motivação dos estudantes em relação aos estudos, gerando, assim, acessibilidade, inclusão e aprendizagens múltiplas. 


\section{Considerações finais}

Tendo em vista que a educação das pessoas com NEEs vem se expandido ao longo dos anos, tanto pela representatividade dos estudantes que têm acessado as redes de ensino quanto pela ampla variedade dos casos, sendo alguns de alta complexidade, consideramos que a capacitação dos educadores que atuam nas instituições educativas é fator determinante para a construção de uma educação inclusiva. Por educação inclusiva, entendemos aquela capaz de acolher e atender os educandos em suas particularidades de modo que consigam, por meio de estratégias pedagógicas diferenciadas e adaptações curriculares individualizadas, propostas pelos educadores, no sentido de desenvolver as aprendizagens de modo significativo e com qualidade no ensino (PIMENTEL, 2012; SONZA, 2020).

Diante disso, entendemos que a docência na educação inclusiva requer saberes docentes, ou seja, capacitação específica, a qual não se esgota na trajetória inicial da formação dos professores e, sim, precisa ocorrer de modo contínuo, para e na atuação profissional. Por isso, a formação contínua é entendida como processual e inacabada (FREIRE, 1996).

Compreendemos, assim, que as oportunidades formativas precisam ser ampliadas para além dos cursos de formação, pois é nas práticas educativas que se revelam os desafios da docência com estudantes que possuem NEEs, bem como as especificidades da educação inclusiva. Nesse contexto, o projeto de ensino desenvolvido que teve como foco tanto propiciar atendimento pedagógico a alunos com NEEs quanto ampliar a formação de professores pré-serviço para/nas práticas educativas inclusivas, apresentou-se como potente possibilidade de capacitação promovendo, de modo colaborativo, a ampliação dos saberes de educadoras pré-serviço e, em serviço, referentes à acessibilidade e inclusão na educação básica e superior.

Acrescentamos que a atuação das educadoras de modo a promover a acessibilidade e inclusão nas práticas educativas do campus foi proposta e desenvolvida com o suporte teórico-prático oferecido, sobretudo, nos momentos de estudos e diálogos reflexivos estruturados na metodologia de formação colaborativa criada dentro deste projeto de ensino. Com isso, consideramos que saberes necessários à prática educativa inclusiva foram construídos em colaboratividade nos processos de formação inicial e continuada de educadoras pré e em serviço por meio de um projeto de ensino, $\mathrm{o}$ que contribuiu para o desenvolvimento e aprendizagem dos alunos com NEEs atendidos durante o ensino remoto no contexto pandêmico (FREIRE, 1996).

\section{Referências}

AMARAL, Rita Andriele; POSTAY, Julia; FINIMUNDI, Verônica; WINTERHALTER, Diolinda Franciele; MONZÓN, Andrea Jessica. Inclusão, acessibilidade e formação docente: relatos de um projeto de ensino do NAPNE. Anais da Galeria de Projetos, 2021, edição virtual. IFRS - Campus Feliz - IFRS, 2021. Disponível em: <https://galeriadeprojetos. feliz.ifrs.edu.br/ensino/pdfs/ensino_1.pdf>. Acesso em: 06 maio 2021.

BRASIL. Lei no. 9394, de 20 de dezembro de 1996. Estabelece as Diretrizes e Bases da Educação Nacional.

BRASIL. Lei no 11.892, de 29 de dezembro de 2008. Institui a Rede Federal de Educação Profissional, Científica e Tecnológica, cria os Institutos Federais de Educação, Ciência e Tecnologia, e dá outras providências.

BRASIL. Lei no 13.146, de 06 de julho de 2015. Institui a Lei Brasileira de Inclusão da Pessoa com Deficiência (Estatuto da Pessoa com Deficiência).

BRASIL. Base Nacional Comum Curricular: Ensino Fundamental. Brasília, DF: MEC/Conselho Nacional de Educação, 2018a.

BRASIL. Base Nacional Comum Curricular: Ensino Médio. Brasília, DF: MEC/Conselho Nacional de Educação, 2018 b. 
FREIRE, Paulo. Pedagogia da Autonomia: saberes necessários à prática educativa. São Paulo: Paz e Terra, 1996.

INSTITUTO FEDERAL DE EDUCAÇÃO CIÊNCIA E TECNOLOGIA DO RIO GRANDE DO SUL. Resolução nº 020, de 2014. Aprova o Regulamento dos Núcleos de Atendimento às Pessoas com Necessidades Educacionais Específicas (Napne). Disponível em: https://ifrs.edu.br/wp-content/uploads/2017/09/Resolucao-20-14.pdf. Acesso em: 06 maio 2021.

INSTITUTO FEDERAL DE EDUCAÇÃO CIÊNCIA E TECNOLOGIA DO RIO GRANDE DO SUL. Instrução Normativa Proen $\mathrm{n}^{\circ} 05$ de 2020. Normatiza e orienta sobre procedimentos operacionais para prover acessibilidade das atividades pedagógicas não presenciais para estudantes com necessidades educacionais específicas no IFRS. Disponível em: https://ifrs.edu.br/wp-content/uploads/2020/08/IN-05-2020-Procedimentos-operacionais-para-prover-acessibilidade-das-atividades-pedagogicas-nao-presenciais-para-estudantes-com-necessidades-educacionais-especificas-no-IFRS-1.pdf. Acesso em: 11 nov. 2020.

INSTITUTO FEDERAL DE EDUCAÇÃO CIÊNCIA E TECNOLOGIA DO RIO GRANDE DO SUL. Instrução Normativa Proen $n^{\circ}$ 07, de 04 de setembro de 2020. Regulamenta os fluxos e procedimentos de identificação, acompanhamento e realização do Plano Educacional Individualizado (PEI) dos estudantes com necessidades educacionais específicas do IFRS. Disponível em: https://ifrs.edu.br/wp-content/uploads/2020/09/IN-07-2020-Plano-Educacional-Individualizado-PEI.pdf. Acesso em: 11 nov. 2020.

PIMENTEL, Susana. Formação de professores para a inclusão - saberes necessários e percursos formativos. In: MIRANDA, Therezinha; GALVÃO FILHO, Teófilo. O professor e a educação inclusiva. Salvador: EDUFBA, 2012.

POSTAY, Júlia; AMARAL, Rita; WALKER, Gabriele; MONZÓN, Andrea. Inclusão, acessibilidade e formação docente: relatos de um projeto de ensino. Anais do $5^{\circ}$ Salão de Pesquisa, Extensão e Ensino/7º Seminário de Educação Profissional e Tecnológica, 2020, edição virtual. IFRS, 2020. Disponível em: https:/eventos.ifrs.edu.br/index.php/Salao_IFRS/5salao/ paper/viewFile/9165/4883. Acesso em: 06 maio 2021.

SILVA, Lázara Cristina da. Formação de professores: desafios à educação inclusiva. Revista Ibero-Americana de Estudos em Educação, Araraquara, v. 10, n. esp. 1, p. 691-702, 2015. DOI: 10.21723/riaee.v10i5.7920. Disponível em: https:// periodicos.fclar.unesp.br/iberoamericana/article/view/7920. Acesso em: 04 maio 2021.

SONZA, Andrea; VILARONGA, Carla Ariela; MENDES, Edneia. Os NAPNEs e o Plano Educacional Individualizado nos Institutos Federais de Educação. Revista Educação Especial, v. 33, p. 1-24, 2020. Disponível em: https://periodicos. ufsm.br/educacaoespecial/article/view/52842 Acesso em: 06 maio 2021.

SOUZA, Ana Lucia; RODRIGUES, Maria Goretti. Educação inclusiva e formação docente continuada. Anais do 12 Congresso Nacional de Educação. Disponível em: https://educere.bruc.com.br/arquivo/pdf2015/21491_10456.pdf. Acesso em: 15 abril 2021.

TARDIF, Maurice. Saberes docentes e formação profissional. Petrópolis: Editora Vozes, 2012.

TOLEDO, Monica; FAÇANHA, Lorelay; ARRUDA, Edna. Formação docente em colaboração: projeto "Currículo, Identidade e Diversidade”. Cadernos do Aplicação: Pesquisa e Reflexão em Educação Básica, v. 33, n. 1, p. 1-12, 2020.

Data de submissão: 14/05/2021

Data de aceite: $12 / 07 / 2021$ 